\title{
A Procedure for Standardizing MLC Quality Assurance for Elekta Linac
}

\author{
K. Yan
}

Thomas Jefferson University and Hospitals

M. Studenski

Thomas Jefferson University and Hospitals

H. Liu

Thomas Jefferson University and Hospitals

I. Buzurovic

Thomas Jefferson University and Hospitals

Y. Cui

Thomas Jefferson University and Hospitals. Follow this and additional works at: https://jjc.jefferson.edu/bodinejournal

Part of the Oncology Commons

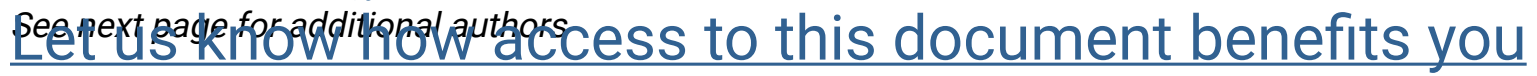

\section{Recommended Citation}

Yan, K.; Studenski, M.; Liu, H.; Buzurovic, I.; Cui, Y.; Shabason, L.; Harrison, A.; Yu, Y.; Hossain, M.; and Xiao, Y. (2010) "A Procedure for Standardizing MLC Quality Assurance for Elekta Linac," Bodine Journal: Vol. 3 : Iss. 1 , Article 19.

DOI: https://doi.org/10.29046/TBJ.003.1.018

Available at: https://jdc.jefferson.edu/bodinejournal/vol3/iss1/19

This Article is brought to you for free and open access by the Jefferson Digital Commons. The Jefferson Digital Commons is a service of Thomas Jefferson University's Center for Teaching and Learning (CTL). The Commons is a showcase for Jefferson books and journals, peer-reviewed scholarly publications, unique historical collections from the University archives, and teaching tools. The Jefferson Digital Commons allows researchers and interested readers anywhere in the world to learn about and keep up to date with Jefferson scholarship. This article has been accepted for inclusion in Bodine Journal by an authorized administrator of the Jefferson Digital Commons. For more information, please contact: JeffersonDigitalCommons@jefferson.edu. 


\section{A Procedure for Standardizing MLC Quality Assurance for Elekta Linac}

Authors

K. Yan, M. Studenski, H. Liu, I. Buzurovic, Y. Cui, L. Shabason, A. Harrison, Y. Yu, M. Hossain, and Y. Xiao 


\section{A Procedure for Standardizing MLC Quality Assurance for Elekta Linac}

Yan, K., ${ }^{1}$ Studenski, M., ${ }^{1}$ Liu, H., ${ }^{1}$ Buzurovic, l., ${ }^{1}$ Cui, Y., ${ }^{1}$ Shabason, L., ${ }^{1}$ Harrison, A., ${ }^{1}$ Yu, Y., ${ }^{1}$ Hossain, M., ${ }^{2}$ Xiao, Y. ${ }^{1}$

${ }^{1}$ Department of Radiation Oncology, Thomas Jefferson University and Hospitals, Philadelphia, PA

${ }^{2}$ Fox Chase Cancer Center, Philadelphia, PA

\section{Purpose}

As specified in TG142, MLC position accuracy needs to be tested on weekly/monthly basis, with $1 \mathrm{~mm}$ tolerance. This study focuses on developing techniques, hardware and software tools for implementation of MLC QA tests for Elekta Linacs.

\section{Method and Materials}

This process was tested with an Elekta Synergy S, Beam Modulator ${ }^{\mathrm{TM}}$, which has 40 leaf pairs of $4 \mathrm{~mm}$ width (maximum $16 \mathrm{~cm} \times 21 \mathrm{~cm}$ field size). Based on the machine characteristics, two picket-fence IMRT plans were designed: one has $52 \mathrm{cmx} 16 \mathrm{~cm}$ strips separated by $2 \mathrm{~cm}$ gap; the other has the same setup with individual leafs intentionally displaced by $\pm 1 \mathrm{~mm}, \pm 1.2 \mathrm{~mm}$, etc. Both plans used $6 \mathrm{MV}$ x-rays and $50 \mathrm{MU}$ on each strip. We overcame the limitation of Xio planning system in generating picket-fence IMRT plan by modifying leaf positions from a DICOM RT plan file. In-house software was executed to validate the files before imported into Record and Verify system (Mosaiq) for delivery. Radiographic images were acquired using Kodak XV films. The borders of a $16 \mathrm{~cm} \times 21 \mathrm{~cm}$ light field were first traced on the film. These reference lines helped reduce the orientation errors during image registration. Two sets of films were exposed with full buildup. After development, each film was digitized with $0.06 \mathrm{~mm}$ resolution using a high-resolution scanner. The images were then imported into Matlab. Inhouse code was used to detect leafs exceeding the $1 \mathrm{~mm}$ threshold.

\section{Results}

The plans were delivered smoothly. Leaf positions in the first image were used as baselines, instead of using reference leaf positions from the same exposure. This reduced systematic errors. After image registration, leafs displacing from the baseline by 16 pixels $(1 \mathrm{~mm})$ or more were detected.

\section{Conclusion}

This efficient procedure provides a sufficiently accurate test for MLC positioning reproducibility. It is a simple and straightforward procedure that can be used for routine MLC position checks.. 